\title{
Substrato alternativo para produção de mudas de mamoeiro formosa (cv. Caliman)
}

\author{
Alternative substrate for the production of formosa papaya \\ seedlings (cv. Caliman)
}

\author{
Francisca Gislene ALBANO $^{1 *}$; Adenaelson Sousa MARQUES $^{2}$; \\ Ítalo Herbert Lucena CAVALCANTE \\ ${ }^{1}$ Universidade Federal do Piauí, Campus "Profa. Cinobelina Elvas”, Bom Jesus, PI. gislene.fga@gmail.com \\ ${ }^{2}$ Universidade Federal do Piauí, Campus "Profa. Cinobelina Elvas", Bom Jesus, PI. kdadenaelson@gmail.com \\ ${ }^{3}$ Universidade Federal do Vale do São Francisco, Campus Ciências Agrárias, Petrolina, PE. \\ italo.cavalcante@univasf.edu.br
}

Recebido em: 20-03-2014; Aceito em: 23-06-2014

\begin{abstract}
Resumo
Para o sucesso da cultura do mamoeiro, é essencial uma produção qualificada dos frutos, obtida a partir de mudas de alta qualidade e plantas de elevado potencial genético. Nesse sentido, o presente trabalho objetivou avaliar a viabilidade do caule decomposto de buriti (Mauritia vinifera Mart.) (CDB) na formação de mudas de mamoeiro formosa cv. Caliman. O experimento foi conduzido no município de Bom Jesus-PI. Adotou-se o delineamento inteiramente casualizado, com tratamentos referentes às diferentes formulações de substrato [S1: solo e areia 1:1 (80\%) + CDB (20\%); S2: solo e areia 1:1 $(60 \%)+$ CDB $(40 \%)$; S3: solo e areia 1:1 $(40 \%)+$ CDB $(60 \%)$; S4: solo e areia $1: 1(20 \%)+$ CDB $(80 \%)$; S5: CDB (100\%)]. Foram adotadas cinco repetições com cinco mudas por parcela. Foram registradas as seguintes variáveis: emergência de plântulas, índice de velocidade de emergência, altura de plântula, diâmetro do caule, concentração de clorofila, área foliar, área radicular, comprimento médio de raiz, diâmetro médio radicular, densidade de raízes, massa da matéria seca da parte aérea e de raiz. O CDB pode ser usado como parte integrante do substrato para a formação de mudas de mamoeiro, na proporção de $20 \%$, atuando positivamente na altura de plântulas, diâmetro do caule, área foliar, clorofila foliar, diâmetro radicular, massa da matéria seca da parte aérea e massa da matéria seca radicular.
\end{abstract}

Palavras-chave adicionais: Carica papaya L; qualidade de mudas; substratos regionais.

\begin{abstract}
For the successful cultivation of papaya, fruits of high quality are essential and this starts with seedlings of high genetic potential and quality. The objective of this project was to evaluate the decomposed trunk of buriti (CDB) (Mauritia vinifera Mart.) plants for the formation of seedlings of 'Caliman' $\mathrm{cv}$. of papaya of the formosa type. The experimental units were distributed in the greenhouse (a screen covering which allowed $50 \%$ luminosity) according to a completely random design. The treatments consisted of six formulations of the substrata : S1 : soil and sand $1: 1(80 \%)+$ CDB $(20 \%)$, S2 : soil and sand $1: 1(60 \%)+$ CDB $(40 \%)$, S3 : soil and sand $1: 1(40 \%)+\operatorname{CDB}(60 \%)$, S4 : soil and sand $1: 1(20 \%)+\operatorname{CDB}(80 \%)$, and S5 : CDB (100\%). Each replication of each treatment was formed by five seedlings. The evaluated variables were the following : seedling emergence, speed of emergence index, seedling height, stem diameter, chlorophyll concentration, leaf area, radicular area, mean root length, mean radicular diameter, root density, and mean aerial part and root dry mass. The results showed that CDB can be used at the proportion of $20 \%$ to compose substrata for the development of papaya seedlings. This formulation favors plant height, stem diameter, leaf area, leaf chlorophyll, radicular diameter, aerial part and root dry mass.
\end{abstract}

Additional keywords: Carica papaya L; regional substrates; seedling quality.

Introdução

O mamoeiro (Carica papaya L.) é uma frutífera cultivada praticamente em todo o Brasil (FAO, 2013), registrando-se em 2010 a produção de 1.875.000 toneladas de frutos (IBGE, 2014), o que lhe caracteriza cultura de grande importância econômica.

O sistema produtivo do mamoeiro requer constante renovação dos pomares, num período de aproximadamente 2,5 a 4 anos, 0 que demanda atenção especial à aquisição de sementes, ao substrato e ao preparo das mudas de forma geral (CAVALCANTE et al., 2011a). 
Nesse sentido, para a obtenção de mudas de alta qualidade com reflexos positivos na produtividade, torna-se fundamental que, na fase de mudas, sejam utilizados substratos com características que favoreçam a germinação das sementes, o desenvolvimento radicular e o crescimento adequado das plantas (RAMOS et al., 2002), permitindo à cultura atingir seu máximo potencial genético no campo.

Para proporcionar condições favoráveis ao desenvolvimento vegetal, o substrato deve apresentar composição uniforme, baixa densidade, alta capacidade de troca catiônica, alta capacidade de retenção de água e boa aeração e drenagem (TERRA et al., 2011).

Assim, estudos têm sido realizados para obtenção de composições que reúnam vários benefícios em um único substrato, mas com baixo custo de obtenção (MELO et al., 2007; FRANCISCO et al., 2010). Especificamente, o mamoeiro tem sido propagado comercialmente via sementes, usando substrato comercial, com elevado custo e sem 0 aproveitamento de materiais regionais com potencial, fato que motiva a execução de projetos de pesquisa envolvendo insumos de disponibilidade e custos reduzidos, mas eficientes no processo de produção e de mudas.

Dentre os materiais regionais que têm potencial para composição de substratos hortí-
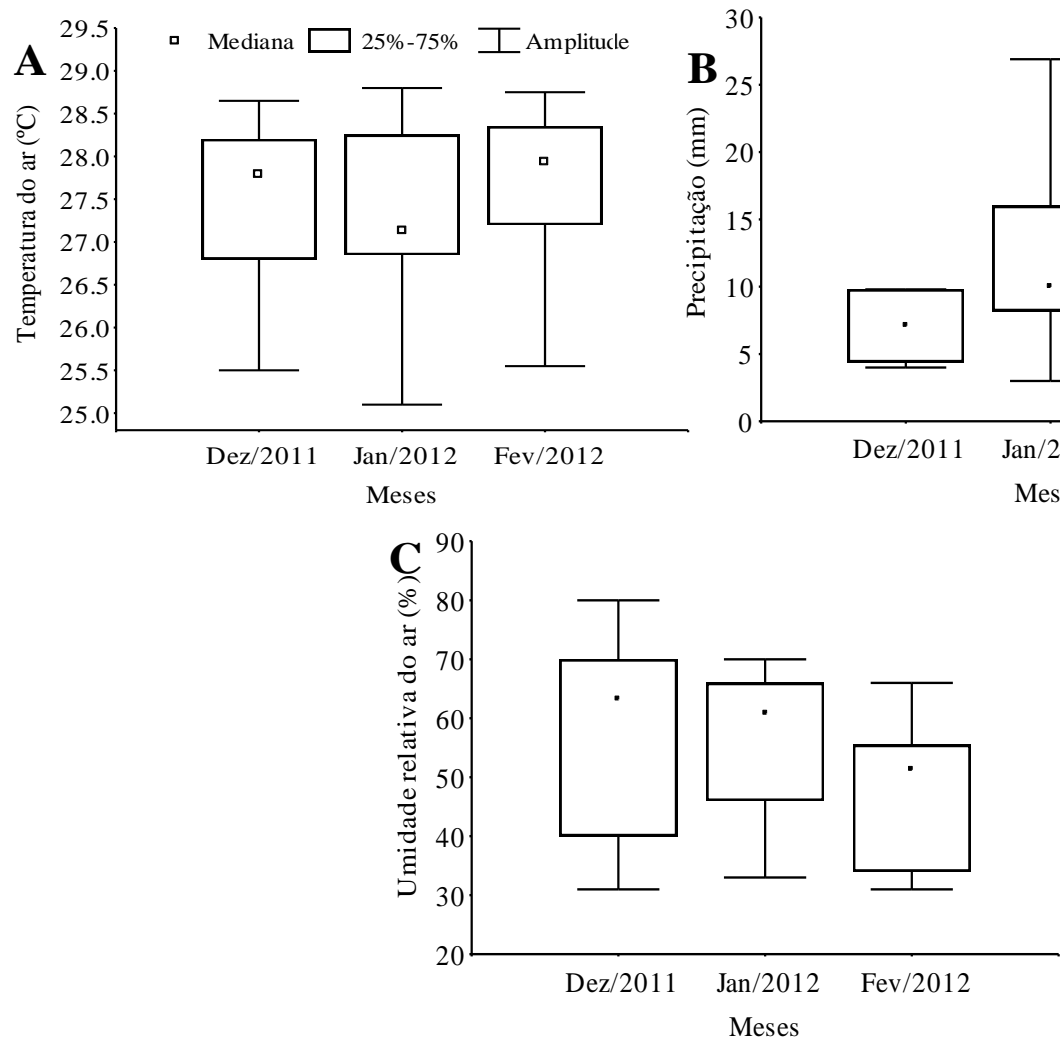

Figura 1 - Temperatura do ar (A), precipitação $(B)$ e umidade relativa do ar (C) durante a execução do experimento. Bom Jesus-PI. Air temperature $(A)$, rain precipitation $(B)$, and air relative humidity $(C)$ during the duration of the experimente.

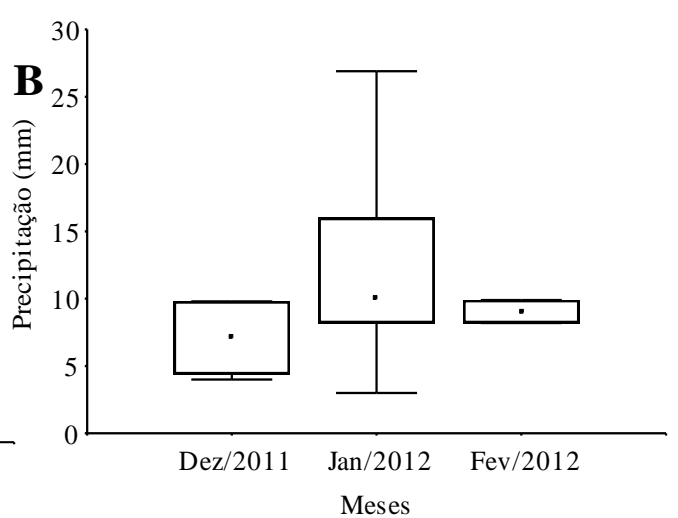

colas, destaca-se o caule decomposto de buriti (Mauritia vinifera Mart.), popularmente conhecido como pau-de-buriti, que foi testado com sucesso para espécies frutíferas nativas como castanheira-do-gurgueia (CALVACANTE et al., 2011b), e espécies de importância econômica, como maracujazeiro (SILVA, 2012) e helicônias (BECKMAM-CAVALCANTE et al., 2011).

Mediante o exposto, o presente trabalho foi desenvolvido com o objetivo de avaliar a viabilidade do caule decomposto de buriti na formação de mudas de mamoeiro formosa cv. Caliman.

\section{Material e métodos}

O experimento foi conduzido de dezembro de 2011 a fevereiro de 2012, com mamoeiro formosa (cv. Caliman) em telado (50\% de luminosidade), no município de Bom Jesus, Piauí. O município de Bom Jesus pertence à região do semiárido piauiense com clima quente e úmido, classificado por Köppen como Cwa.

No interior do telado, foram monitoradas diariamente a temperatura e a umidade relativa do ar, utilizando um termoigrômetro digital (Instrutemp $^{\circledR}$, Brasil), além da precipitação fora do telado. Os dados das variáveis climáticas monitoradas encontram-se na Figura 1. 
Adotou-se o delineamento inteiramente casualizado, com cinco tratamentos referentes às diferentes proporções de caule decomposto de buriti (Mauritia vinifera, Mart.) (CDB), no substrato [S1: solo e areia 1:1 (80\%) + CDB (20\%); S2: solo e areia 1:1 (60\%) + CDB (40\%); S3: solo e areia $1: 1(40 \%)+\operatorname{CDB}(60 \%)$; S4: solo e areia $1: 1(20 \%)+$ CDB (80\%); S5: CDB (100\%)], cinco repetições, com cinco mudas por parcela, totalizando 125 mudas.

Para a formação das mudas, foram utilizados sacos plásticos como recipientes, nas dimensões 16 × $26 \mathrm{~cm}$, preenchidos com subs- tratos padronizados, em volume de aproximadamente 2,5 L. As características físicas de cada substrato (tratamento) estudado estão contidas na Tabela 1. Isoladamente, o caule decomposto de buriti apesenta $597,85 \mathrm{~g} \mathrm{dm}^{-3}$ de matéria orgânica, $21,18 \mathrm{~g} \mathrm{~kg}^{-1}$ de $\mathrm{N}, 8,8 \mathrm{cmol}_{\mathrm{c}} \mathrm{dm}^{-3}$ de $\mathrm{Ca}^{2+}$ (extrator $\mathrm{KCl} 1 \mathrm{M}$ ), 7,9 $\mathrm{cmol}_{\mathrm{c}} \mathrm{dm}^{-3}$ de $\mathrm{Mg}$ (extrator $\mathrm{KCl} 1 \mathrm{M}$ ), , 0,0 $\mathrm{cmol}_{\mathrm{c}} \mathrm{dm}^{-3}$ de $\mathrm{Al}^{3+}$ (extrator $\mathrm{KCl} 1 \mathrm{M}$ ), 0,95 $\mathrm{cmol}_{\mathrm{C}} \mathrm{dm}^{-3}$ de $\mathrm{Na}^{+}$(extrator Melich 1), $168,00 \mathrm{mg} \mathrm{dm}^{-3}$ de $\mathrm{P}$ (extrator Melich 1), $404,00 \mathrm{mg} \mathrm{dm}^{-3}$ de $\mathrm{K}^{+}$(extrator Melich 1) e $2,03 \mathrm{mg} \mathrm{dm}^{-3}$ de $B$.

Tabela 1 - Características físicas e químicas dos substratos testados no experimento. Physical and chemical characteristics of the substrata used in the experiment.

\begin{tabular}{cccccccc}
\hline Substratos & $\begin{array}{c}\mathrm{DU} \\
\left(\mathrm{g} \mathrm{L}^{-1}\right)\end{array}$ & $\begin{array}{c}\text { CRA } \\
(\%)\end{array}$ & $\begin{array}{c}\mathrm{VP} \\
(\%)\end{array}$ & $\begin{array}{c}\mathrm{DS} \\
\left(\mathrm{Pa}^{*} \mathrm{MS} / 100\right)\end{array}$ & $\begin{array}{c}\mathrm{EA} \\
(\%)\end{array}$ & $\mathrm{pH}$ & $\begin{array}{c}\mathrm{CE} \\
\left(\mathrm{dS} \mathrm{cm}^{-1}\right)\end{array}$ \\
\hline S1 & 1524,14 & 20,01 & 42,33 & 444,83 & 20,32 & 7,28 & 0,14 \\
S2 & 1245,91 & 42,47 & 63,34 & 265,78 & 20,87 & 5,20 & 1,13 \\
S3 & 1025,76 & 40,84 & 66,98 & 219,49 & 26,13 & 4,93 & 2,20 \\
S4 & 910,77 & 45,18 & 73,39 & 173,21 & 28,21 & 3,71 & 3,00 \\
S5 & 640,92 & 56,03 & 90,72 & 67,52 & 34,70 & 2,68 & 7,00 \\
\hline
\end{tabular}

S1: solo e areia 1:1 (80\%) + CDB (20\%); S2: solo e areia 1:1 (60\%) + CDB (40\%); S3: solo e areia 1:1 (40\%) + CDB (60\%); S4: solo e areia 1:1 (20\%) + CDB (80\%); S5: CDB (100\%); DU: Densidade úmida; CRA: Capacidade de retenção de água; VP: Volume de poros; DS: Densidade seca; EA: Espaço de aeração; CE: Condutividade elétrica.

Foram semeadas duas sementes por saco, sendo o desbaste realizado aos 15 dias após a emergência das plantas, deixando-se apenas a mais vigorosa por recipiente plástico. Semanalmente, foi realizada adubação via foliar com Niphocan ${ }^{\circledR}$ (composição: $10 \%$ de N; $8 \%$ de $\mathrm{P}_{2} \mathrm{O}_{5} ; 8 \%$ de $\mathrm{K}_{2} \mathrm{O} ; 0,5 \%$ de $\mathrm{Mg} ; 1 \%$ de $\mathrm{Ca} ; 2 \%$ de S; $1 \%$ de $\mathrm{Zn} ; 0,5 \%$ de B; $0,1 \%$ de $\mathrm{Fe} ; 0,1 \%$ de Mo; $0,2 \%$ de $\mathrm{Cu}$ e $0,5 \%$ de $\mathrm{Mn}$ ), para o suprimento nutricional das mudas de mamoeiro, totalizando 8 aplicações.

Para a determinação da necessidade de reposição hídrica, os sacos plásticos preenchidos com os respectivos substratos foram saturados com água até atingirem a capacidade de campo e novamente pesados para registro da massa de referência. Diariamente, os sacos foram pesados (balança Balmak Economic ${ }^{\circledR}$ ) e o quantitativo equivalente a $70 \%$ da evaporação foi reposto.

O caule decomposto de buriti utilizado para a formulação dos substratos foi coletado em uma área alagada, conhecida popularmente como "brejo", no município de Palmeira do Piauí-PI.

Para a determinação dos efeitos dos respectivos tratamentos na formação de mudas de mamoeiro formosa, foram registradas as seguintes variáveis: i) Emergência de plântulas (\%): contagem do número de plântulas emergidas a cada dois dias, a partir do início da emergência (plântula que apresentava as folhas cotiledonares abertas) até a estabilização; ii) índice de velocidade de emergência (IVE): calculado de acordo com Maguire (1962); ao término do experimento, 80 dias após a semeadura, foram analisadas;iii) altura de plântula $(\mathrm{cm})$ : determinada do nível do solo ao ápice da plântula: com auxílio de régua milimetrada; iv) diâmetro do caule $(\mathrm{mm})$ : obtido com paquímetro digital (Digimess $^{\circledR}$ ), a $10 \mathrm{~cm}$ de altura; v) concentração de clorofila (índice): foi determinada em folhas sadias, através de clorofilômetro (Falker ${ }^{\circledR}$, Brasil). Em cada parcela, escolheram-se três folhas para a obtenção de uma média representativa de cada parcela, efetuando-se três leituras distribuídas em cada folha, na base, parte mediana e ápice da folha, conforme recomendações de El-Hendawy et al. (2005).

As plântulas foram retiradas dos substratos, lavadas em água corrente e conduzidas ao laboratório de Fitotecnia da UFPI, onde foram avaliadas as variáveis: i) área foliar, determinada em medidor de área foliar digital (Li-Cor, L1-3100 ${ }^{\circledR}$ ); ii) área radicular $\left(\mathrm{mm}^{2}\right)$; iii) comprimento médio de raiz (mm); iv) diâmetro médio radicular $(\mathrm{mm})$; v) densidade de raízes $\left(\mathrm{m} / \mathrm{mm}^{2}\right)$ : estas variáveis foram coletadas através do Delta-T SCAN ${ }^{\circledR}$ versão 2.04; vi) massa da matéria seca da parte aérea e de raiz (g): obtidos pelo método da secagem em estufa com circulação forçada de ar, à temperatura de $65^{\circ} \mathrm{C}$, até atingir massa constante.

Os dados foram submetidos à análise de variância, pelo teste "F", para diagnóstico de efeito 
significativo, e aquelas variáveis que apresentaram efeito significativo foram submetidas à análise quantitativa de regressão polinomial, no software Sigmaplot (SPSS, 2000), conforme recomendações de Ferreira (2000). Também foi realizada análise de correlação entre as variáveis dependentes e as características dos substratos contidos na Tabela 1.

\section{Resultados e discussão}

Dentre todas as variáveis estudadas, não se registrou efeito significativo das diferentes composições de substratos para área radicular, comprimento médio de raiz e densidade de raízes.

A constatação de diferença significativa para o índice de velocidade de emergência (IVE) (Figura 2A), entre as diferentes composições de substratos, concorda com resultados encontrados por Silva (2012), que também utilizou caule decomposto de buriti [Mauritia vinifera, Mart. (CDB)] na produção de mudas de maracujazeiro e encontrou superioridade no substrato $100 \%$ de CDB. Francisco et al. (2010) realizaram estudo com diversos substratos, dentre os quais solo + esterco, e obtiveram índices superiores aos substratos do presente trabalho, exceto para aquele composto por $80 \%$ de CDB.

De forma análoga ao IVE, houve incremento da emergência de plântulas (EP) do mamoeiro em função da maior proporção de CDB na composição do substrato (Figura 2B), o que pode ser atribuído à correlação positiva e significativa entre essa variável e o volume de poros dos respectivos substratos $(r=0,93)$.
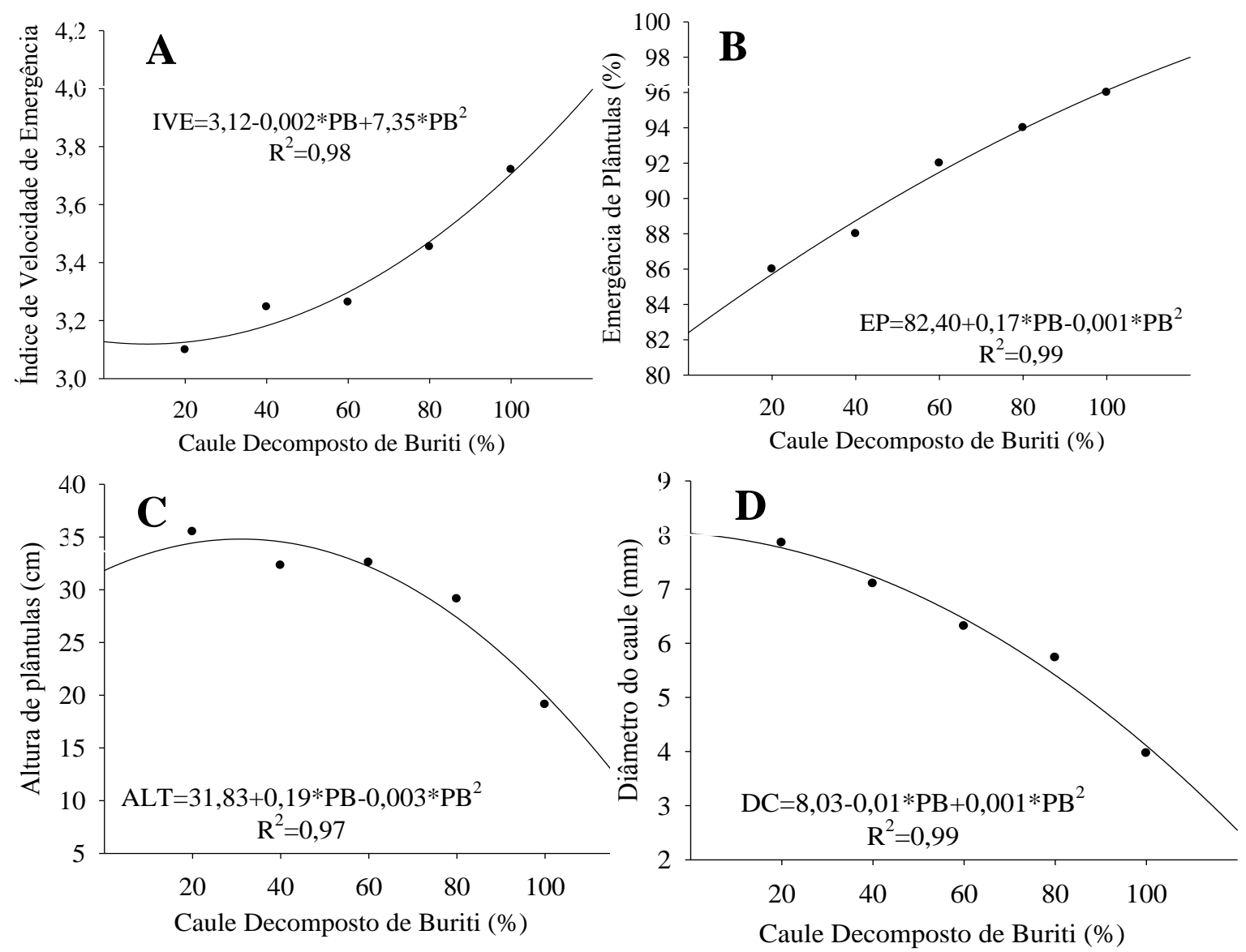

Figura 2. Índice de velocidade de emergência (A), emergência de plântulas (B), altura de plântulas (C) e diâmetro do caule (D), de mudas de mamoeiro formosa cv. Caliman, em função dos substratos com diferentes composições de caule decomposto de buriti. Bom Jesus-PI. Speed of emergence index $(A)$, seedling emergence $(B)$, seedling height $(C)$, and stem diameter $(D)$ of papaya seedlings as influenced by substrata with different proportions of $C D B$

A emergência de plântulas (EP) iniciouse em média, aos 10 dias após a semeadura, resultado que concorda com o encontrado por Costa et al. (2009), que obtiveram a mesma mé- dia de emergência de plântulas e contrariam os resultados de Galvão et al. (2007) e Silva et al. (2011), os quais registram que o início da emergência ocorreu por volta do $20^{\circ}$ e $30^{\circ}$ dia após a 
semeadura, respectivamente, mesmo estando estes em condições semelhantes de temperatura e umidade do ar e trabalhando com substratos com percentual de matéria orgânica semelhante ao observado para o caule decomposto de butiri $\left(594,58 \mathrm{~g} \mathrm{dm}^{-3}\right)$. Quantitativamente, as médias contidas na Figura $2 \mathrm{~B}$ são compatíveis com as registradas por Cavalcante et al. (2012), em estudo contendo biochar no substrato, para produção de mudas de maracujazeiro-amarelo.

As maiores alturas de plântulas (AP) (Figura 2C) foram encontradas no substrato S1, S2 e S3, alcançando valores médios de 35; 32 e 33 $\mathrm{cm}$, respectivamente. Observa-se que, com 0 aumento da concentração de CDB para $100 \%$ (S5), a AP foi reduzida em $42,42 \%$ em relação ao $\mathrm{S} 1$, resultados compatíveis com os apresentados por Silva (2012), nas mesmas proporções de CDB. Por outro lado, os resultados médios da Figura $2 \mathrm{C}$ são inferiores ao estudo realizado por Pereira et al. (2008), que testaram substrato composto de caulim, terra e esterco, em que a composição de $22 \%$, 29\% e $39 \%$, respectivamente, atingiram valores máximos de $54 \mathrm{~cm}$ de altura.

$A$ redução na $A P$ com maiores proporções de CDB ocorreu devido ao efeito direto de duas características dos substratos: $0 \mathrm{pH}$ e a condutividade elétrica (CE). Houve incremento significativo da correlação negativa e altamente significativa (FERREIRA, 2000) entre a CE e a AP $\left(r=-0,99^{\star \star}\right)$; e correlação positiva e significativa $\left(r=0,89^{* *}\right)$ entre o $\mathrm{pH}$ do substrato e a variável $\mathrm{AP}$, visto que a redução da $\mathrm{AP}$ acompanhou a diminuição do $\mathrm{pH}$ do substrato.

Adicionalmente, Negreiros et al. (2005), estudando diferentes substratos na formação de mudas de mamoeiro, obtiveram melhores resultados de altura de plântulas com o substrato composto por esterco de curral, solo, areia e vermiculita, na proporção de 2:1:1:1, alcançando $31,45 \mathrm{~cm}$ de altura; portanto, resultado inferior aos substratos S1, S2 e S3, que atingiram 35,5; 32,3 e $32,6 \mathrm{~cm}$ de AP, respectivamente. No que se refere ao diâmetro do caule (DC) (Figura 2D), observa-se que as plântulas cultivadas no substrato S1 obtiveram melhor desenvolvimento, atingindo $8 \mathrm{~mm}$ de $\mathrm{DC}$ ao final do experimento. $\mathrm{O}$ aumento das concentrações de CDB proporcionou decréscimo gradativo desta variável, reduzindo o valor do DC para a metade (4 mm) nas plântulas cultivadas no substrato $S 5$, resultado atribuído principalmente ao incremento da CE do substrato com o aumento de CDB no substrato, visto que houve correlação negativa e significativa entre a CE do substrato e o $D C\left(r=-0,99^{* *}\right)$, i.e., substratos com maiores valores de CE apresentaram as menores médias de DC. Os resultados do presente substrato são inferiores aos reportados por PEREIRA et al. (2008) que ao estudarem o crescimento de mudas de mamo- eiro em substratos contendo caulim (minério composto de silicatos hidratados de alumínio, como a caulinita e a haloisita, e apresenta utilidade como substrato devido à sua estrutura fina e leve, ideal para garantir propriedades sensórias e reológicas delicadas), obtiveram valores máximos de $12,5 \mathrm{~mm}$ de DC para as plântulas cultivadas no substrato composto por $22 \%$ de caulim, $29 \%$ de terra e $39 \%$ de esterco;por outro lado, os valores encontrados no presente trabalho superam os reportados por SILVA et al. (2011), que avaliando a qualidade de mudas de mamoeiro cultivadas em diferentes substratos comerciais e orgânicos, alcançaram 5,68 e 7,36 mm de DC para os substratos Plantmax ${ }^{\circledR}+$ areia lavada $e$ Plantmax ${ }^{\circledR}+$ húmus de minhoca, respectivamente. De forma elucidativa, CAVALCANTE et al. (2010), estudando fontes e níveis da salinidade da água na formação de mudas de mamoeiro, explicam que o aumento da condutividade elétrica resulta na inibição do crescimento em altura, diâmetro do caule e área foliar, devido à diminuição na absorção de água, redução na taxa fotossintética e toxicidade de íons, mais especificamente $\mathrm{Na}^{+}$e $\mathrm{Cl}^{-}$, o que também pode ter ocorrido no presente trabalho.

Como pode ser observado na Figura $3 \mathrm{~A}$, as maiores médias para área foliar foram alcançadas nos substratos S1 e S2, com valores de 332,50 e $319,54 \mathrm{~cm}^{2}$, resultados superiores aos de MELO et al. (2007), que obtiveram valores máximos de $269,87 \mathrm{~cm}^{2}$ para as plântulas de mamoeiro cultivadas em substratos compostos por $45 \mathrm{~mL}$ de esterco de galinha $+135 \mathrm{~mL}$ de palha de arroz carbonizada $+120 \mathrm{~mL}$ de terra vegetal.

Com o aumento da área foliar, as plântulas obtêm maior taxa de assimilação de luz e possibilidade de realização de fotossíntese com consequente acúmulo de matéria seca e maior altura (MELO et al., 2007), situação comprovada pela correlação significativa $(r)$ de $0,94^{*} ; 0,99^{* *}$; $0,99^{* *}$ e $0,98^{* *}$, entre a área foliar e as variáveis $A P, D C$, massa da matéria seca da parte aérea (MSPA) e massa da matéria seca radicular (MSR), respectivamente.

O aumento da capacidade de retenção de água (CRA) do substrato $(p<0,05)$ e $(r)$ de 0,94 influenciou positivamente na área foliar (Figura $3 \mathrm{~A})$, pois quanto menor a concentração de CDB no substrato, menor foi a CRA, já que areia é um material poroso que facilita a aeração, e o caule de buriti é também um material de boa aeração e boa capacidade de retenção de água. Por outro lado, o substrato com $100 \%$ de CDB proporcionou excesso de umidade, o que não é benéfico, uma vez que, segundo BEZERRA (2003), o excesso de água pode propiciar condições anaeróbias em torno das raízes, reduzindo a respiração e limitando a fotossíntese e, ainda, favorecendo o aparecimento de doenças foliares e do solo. 
Paralelamente, verifica-se que a área foliar se correlacionou negativamente com a CE do substrato e positivamente com o pH do substrato, indicando efeito também dos caracteres químicos do substrato na área foliar.
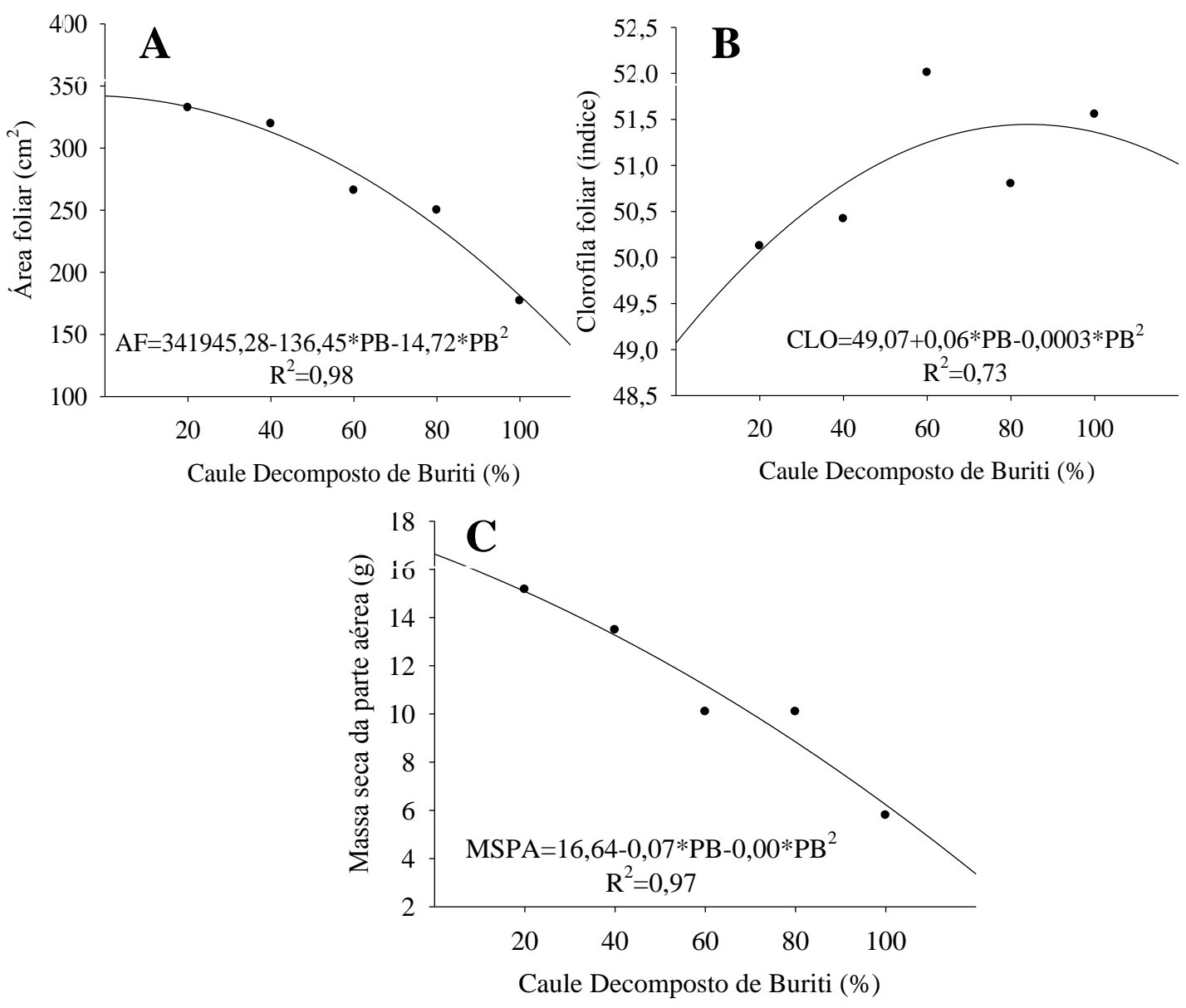

Figura 3. Área foliar (A), clorofila (B) e massa da matéria seca da parte aérea (C) de mudas de mamoeiro formosa cv. Caliman, em função dos substratos com diferentes composições de caule decomposto de buriti. Bom Jesus-PI. Leaf area (AF), chlorophyll (B), and aerial part dry mass (C) of papaya seedlings as influenced by substrata with different proportions of $C D B$.

De acordo com CAVALCANTE et al. (2010), a elevação da CE pode reduzir a disponibilidade de água, o aumento da taxa de respiração, altera a nutrição mineral, a instabilidade da membrana e provoca falha na manutenção de turgor celular, o que tem reflexos negativos na área foliar de muitas culturas, inclusive do mamoeiro.

Para a clorofila foliar (Figura 3B), obsenvse incremento até o substrato S3 seguido de decréscimo; entretanto, a variação entre o menor índice $(S 1=50,1)$ e o maior índice $(S 3=52,0)$ é pequena, ou seja, a concentração de CDB proporcionou pouca influência para esta variável. Resultados semelhantes foram encontrados por SILVA (2012), que testou CDB nessas mesmas proporções, na ausência e na presença de boro, para a cultura do maracujazeiro. Nenhum dos atributos físicos e químicos do substrato bem como das variáveis em estudo se correlacionaram significativamente com a clorofila.

Para o diâmetro radicular, o aumento da concentração de CDB, representado por S5, proporcionou aumento de $14,41 \%$ comparado ao substrato S1 (Figura 4A), resultados semelhantes aos encontrados por MAUAD et al. (2004). Adicionalmente, MALAVOLTA \& ROMERO (1975) explicam que a ausência da quantidade adequada de aeração no substrato torna as raízes mais grossas, curtas e escurecidas, apresentando pequena quantidade de pelos absorventes, comprometendo 0 desenvolvimento da parte aérea, o que não ocorreu no presente trabalho, pois o diâmetro apresentado é pertinente à média geral das raízes de cada tratamento, indicando que houve aumento do diâmetro radicular, mas não apenas da raiz principal. Em complemento, o diâmetro radicular foi positivamente correlacionado $(r=$ $0,94^{\star}$ ) ao volume de poros do substrato. 


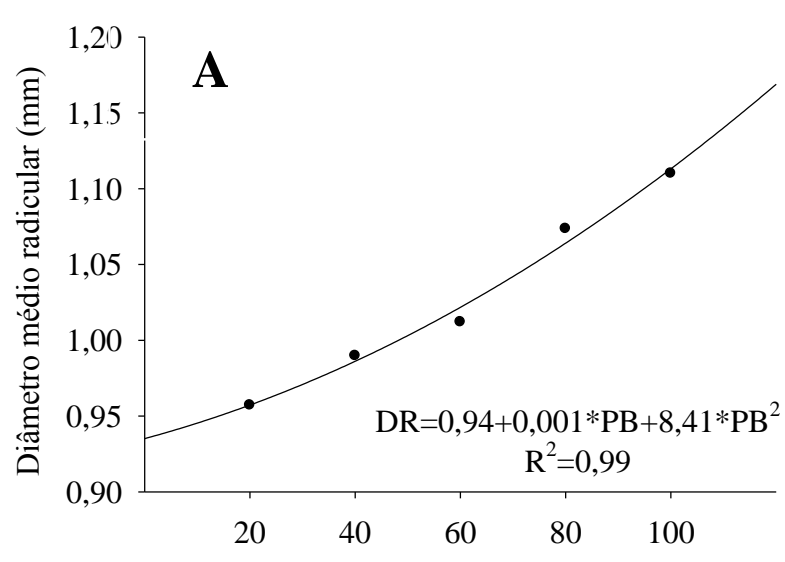

Caule Decomposto de Buriti (\%)

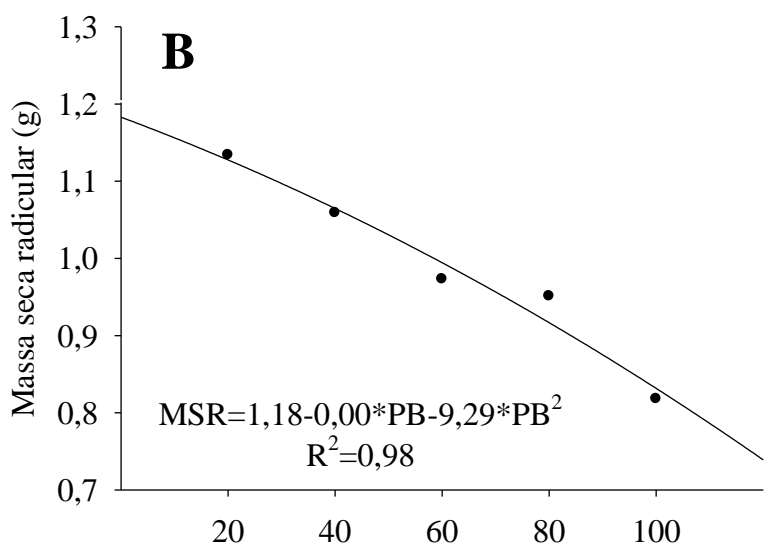

Caule Decomposto de Buriti (\%)

Figura 4. Diâmetro radicular(A) e massa da matéria seca radicular $(B)$ de mudas de mamoeiro Formosa cv. Caliman, em função dos substratos com diferentes composições de caule decomposto de buriti. Bom Jesus-PI. Radicular diameter $(A)$ and radicular dry mass of papaya seedlings as influenced by substrata with different proportions of $C D B$.

A massa da matéria seca da parte aérea (MSPA) e a massa da matéria seca radicular (MSR) seguiram a mesma tendência (Figuras 3C e 4B), i.e., os melhores resultados foram verificados nos substratos que contêm $20 \%$ e $40 \%$ de CDB, com médias superiores $(61,81 \%$ e $57,05 \%$, respectivamente) ao S5 (100\% de CDB), para a variável MSPA, enquanto a MSR no S1 foi superior $27,87 \%$ em relação ao S5. Estes resultados são superiores aos encontrados por MENDONÇA et al. (2006), que estudaram o crescimento de mudas de mamoeiro em substratos, com a utilização de composto orgânico e superfosfato simples, e encontram o valor máximo de $3,85 \mathrm{~g}$ para MSPA e $0,51 \mathrm{~g}$ para MSR, ambos inferiores às menores médias encontradas no S5.

Uma das razões da superioridade do $S 1$, em ambas as variáveis, dá-se pelo fato de que este substrato contém $80 \%$ de areia e solo, que facilitam a aeração, pois segundo MALAVOLTA \& ROMERO (1975), o oxigênio é necessário para a respiração das raízes, e este é retirado dos interstícios existentes no substrato; portanto, se a aeração for deficiente, por exagerada compactação ou excesso de água, o desenvolvimento radicular fica comprometido, fato provavelmente ocorrido no substrato S5 que proporcionou excesso de umidade. Outro fator pertinente refere-se também ao $\mathrm{pH}$ e CE do S1, que apresentou $\mathrm{pH}$ mais elevado e CE mais baixa em relação aos outros substratos, fato que se caracterizou como positivo para a formação de mudas de mamoeiro com qualidade.

\section{Conclusões}

Ao se considerar efeitos positivos do caule decomposto do buriti, especialmente em variáveis como área foliar, massa da matéria seca da parte aérea e massa da matéria seca radicular, conclui-se que o substrato composto por $20 \%$ de caule decomposto de buriti $+80 \%$ de solo e areia (proporção 1:1) pode ser recomendado para a produção de mudas de mamoeiro formosa (cv. Caliman).

\section{Referências}

ALMEIDA, J. P. N. A.; DANTAS, L. L. G. R.; PEREIRA, E. C.; TOSTA, M. S.; MEDEIROS, P. V. Q. Composição de substratos alternativos com capítulo de girassol na produção de mudas de mamoeiro. Revista Verde de Agroecologia e Desenvolvimento Sustentável, Mossoró, v.6, n.1, p.174-178, 2011.

ARAÚJO, J. G.; ARAÚJO JÚNIOR, M. M.; MENEZES, R. H. N.; MARTINS, M. R.; LEMOS, R. N. S.; CERQUEIRA, M. C. Efeito do recipiente e ambiente de cultivo sobre o desenvolvimento de mudas de mamoeiro cv. sunrise solo. Revista Brasileira de Fruticultura, Jaboticabal, v.28, n.3, p.526-529, 2006.

BECKMANN-CAVALCANTE, M. Z.; AMARAL, G. C.; CAVALCANTE, Í. H. L.; LIMA, M. P. D. Alternative substrates for production of Heliconia psittacorum L. seedlings under shade and open field conditions. African Journal of Biotechnology, Nairobi, v.10, n.88, p.1527215277, 2011.

BEZERRA, F. C. Produção de mudas de hortaliças em ambientes protegidos. Fortaleza: Embrapa Agroindústria Tropical, 2003. 22p. (Documento, 72).

BORGES, A. L.; LIMA, A. A.; CALDAS, R. C. Adubação orgânica e química na formação de mudas de maracujazeiros. Revista Brasileira de Fruticultura, Jaboticabal, v.17, n.2, p.17-22, 1995. 
CANESIN, R. C. F. S.; CORRÊA, L. S. Uso de esterco associado à adubação mineral na produção de mudas de mamoeiro (Carica papaya L.). Revista Brasileira de Fruticultura, Jaboticabal, v.28, n.3, p.481-486, 2006.

CAVALCANTE, Í. H. L.; SILVA, R. R. S.; ALBANO, F. G.; LIMA, F. N.; MARQUES, A.S. Foliar Spray of Humic Substances on Seedling Production of Papaya (Pawpaw). Journal of Agronomy, New York, v.10, p.118-122, 2011 a.

CAVALCANTE, Í. H. L.; ROCHA, L. F.; SILVA JUNIOR, G. B.; FALCÃO NETO, R.; SILVA, R. R. $\mathrm{S}$. Seedling production of gurguéia nut (Dypterix lacunifera Ducke) I: seed germination and suitable substrates for seedlings. International Journal of Plant Production, Gorgan, v.5, n.4, p.319-322, $2011 \mathrm{~b}$.

CAVALCANTE, L. F.; CORDEIRO, J. C.; NASCIMENTO, J. A. M.; CAVALCANTE, I. H. L.; DIAS, T. J. Fontes e níveis da salinidade da água na formação de mudas de mamoeiro cv. Sunrise solo. Semina: Ciências Agrárias, Londrina, v.31, n.1, p. 1281-1290, 2010.

COSTA, E.; SANTOS, L. C. R.; VIEIRA, L. C. R. Produção de mudas de mamoeiro utilizando diferentes substratos, ambientes de cultivo e recipientes. Engenharia Agrícola, Jaboticabal, v.29, n.4, p.528-537, 2009.

COSTA, E; SANTOS, L. C. R; CARVALHO, C.; LEAL, P. A. M.; GOMES, V. A. Volumes de substratos comerciais, solo e composto orgânico afetando a formação de mudas de maracujazeiroamarelo em diferentes ambientes de cultivo. Revista Ceres, Viçosa, MG, v.58, n.2, p.216-222, 2011.

El-HENDAWY, S.; HU, Y.; SCHIMIDHALTER, U. Growth, ion content, gasex change, and water relations of wheat genotypes differing in salt tolerances. Australian Journal of Agricultural Research, Melbourne, v.56, n.2, p.123-134, 2005.

FAO - Food and Agriculture Organization. Faostat Disponível em: <http://www.faostat.org.br>.Acesso em:15 mar. 2012.

FERREIRA, P. V. Estatística experimental aplicada à Agronomia. 3.ed. Maceió: UFAL, 2000. 604p.

FRANCISCO, M. G. S.; MARUYAMA, W. I.; MENDONÇA, V; SILVA, E. A.; REIS L. L.; LEAL, S. T. Substratos e recipientes na produção de mudas de mamoeiro 'Sunrise Solo'. Revista Agrarian, Dourados, v.3, n.9, p.267-274, 2010.

GALVÃO, R. O. G; ARAÚJO NETO, S. E.; SANTOS, F. C. B.; SILVA, S. S. Desempenho de mudas de mamoeiro $\mathrm{cv}$. sunrise solo sob diferentes substratos orgânicos. Revista Caatinga, Mossoró, v.20, n.3, p.144-151, 2007.

IBGE - Instituto Brasileiro de Geografia e Estatística. Levantamento sistemático da produção agrícola. Disponível em:<http://www.ibge.gov.br/>. Acesso em: 18 jun. 2012.
MAGUIRE, J. D. Speed of germination - aid in selection aid evolution for sudling emergence and vigor. Crop Science, Madison, v.2, n.2, p.176-177, 1962.

MALAVOLTA, E.; ROMERO, J. P. Manual de adubação. 2. ed. São Paulo: ANDA, 1975. 346p.

MAUAD, M.; FELTRAN, J. C.; CORRÊA, J. C.; DAINESE, R. C.; ONO, E. O.; RODRIGUES, J. D. Enraizamento de estacas de azaléia tratadas com concentrações de ana em diferentes substratos. Ciência e Agrotecnologia, Lavras, v.28, n.4, p.771-777, 2004.

MELO, A. S.; COSTA, C. X.; BRITO, M. E. B.; VIÉGAS, P. R. A.; SILVA JÚNIOR, C. D. Produção de mudas de mamoeiro em diferentes substratos e doses de fósforo. Revista Brasileira de Ciências Agrárias, Recife, v.2, n. 4, p.257-261, 2007.

MENDONÇA, V.; ABREU, N. A. A.; GURGEL, R. L. S.; FERREIRA, E. A.; ORBES, M. Y.; TOSTA, M. S. Crescimento de mudas de mamoeiro formosa em substratos com utilização de composto orgânico e superfosfato simples. Ciência e Agrotecnologia, Lavras, v.30, n.5, p.861-868, 2006.

NEGREIROS, J. R. S.; BRAGA, L. R.; ÁLVARES, V. S.; BRUCKNER, C. H. Diferentes substratos na formação de mudas de mamoeiro do grupo solo. Revista Brasileira de Agrociência, Pelotas, v.11, n.1, p.101-103, 2005.

PEREIRA, W. E.; SOUSA, G. G.; ALENCAR, M. L.; MENDONÇA, R. M. N.; SILVA, G. L. Crescimento de mudas de mamoeiro em substratos contendo caulim. Revista Verde de Agroecologia e Desenvolvimento Sustentável, Mossoró, v.3, n.1, p 27-35, 2008.

RAMOS, J. D.; CHLFUN, N. N. J.; PASQUAL, M.; RUFINI, J. C. M. Produção de mudas de plantas frutíferas por semente. Informe Agropecuário, Belo Horizonte, v.23, n.216, p.64-72, 2002.

SILVA, F. C.; ALVES, F. Q. G.; ALVES, F. G.; RESENDE, J. C. F.; CUNHA, L. M. V. Qualidade de mudas de mamoeiro utilizando diferentes substratos comerciais e orgânicos. In: VII CONGRESSO BRASILEIRO DE AGROECOLOGIA, v.6, n.2, 2011, Fortaleza, Resumos expandidos... Fortaleza: Cadernos de Agroecologia, 2011. CD-ROM.

SILVA, R. R. S. Substratos e boro para produção de mudas de maracujazeiro amarelo. 2012. 52 f. Dissertação (Mestrado em Solos e Nutrição de Plantas) - Universidade Federal do Piauí, Bom Jesus, 2012.

TERRA, S. B.; FERREIRA, A. A. F.; PEIL, R. M. N.; STUMPF, E. R. T.; BECKMANN-CAVALCANTE, M. Z.; CAVALCANTE, Í. H. L. Alternative substrates for growth and production of potted chrysanthemum (cv. Funny). Acta Scientiarum Agronomy, Maringá, v.33, p.465-471, 2011. 